J. Perinat. Med. 17 (1989) 33

\section{Determination of the minimum number of cardiac cycles necessary to ensure representative blood flow velocity measurements}

\author{
Juozas Kurmanavichius', Hans Baumann², Renate Huch², and Albert Huch' \\ ${ }^{1}$ Department of Obstetrics and Gynecology, University of Vilnius, Lithuania, \\ USSR, ${ }^{2}$ Department of Obstetrics, University Hospital of Zurich, Zurich, Switzer- \\ land
}

\section{Introduction}

The evaluation of blood flow velocity waveforms by using Doppler ultrasound represents a new and important advance in both fetal and adult medicine. Using Doppler ultrasound for measurement of blood flow velocity in clinical situations, one has to be aware of several sources of error which could influence the results. Some of these, such as the choice of sample volume and cross-sectional area of the vessel, estimation of the angle of approach, Doppler signal processing and certain other practical factors have been reviewed elsewhere $[3,5,8,9]$. Some of these problems can be overcome by using dimensionless indices. However, the question still remains open as to the optimal number of cardiac cycles necessary for calculation of representative values of blood flow velocity indices. The table presents data on cardiac cycles used by different authors to calculate the pulsatility index (PI), the resistance index (RI) and other blood flow velocity waveform indices $[1,6$, $7,13,14,15,17,19,20,21]$. As we see from the table, there is a wide variation in the number of cycles used for calculations. In this present study we determined the minimum number of cardiac cycles necessary to ensure calculation of representative blood flow indices.

\section{Materials and methods}

Doppler blood flow examinations had been made with a combined pulsed Doppler and a real-time ultrasound system, Acuson 128 (Acuson Computed Sonography, USA); Doppler frequency shifts were recorded on tape using a Sony hi-fi stereo tape recorder.

\section{Curriculum vitae}

Juozas J. KuRmanaviCHIUS, M.D., was born in 1954 in Lithuania, USSR. He received his M. D. from The Vilnius State University, Lithuania, in 1977 and qualified as an obstetrician and gynecologist. Since 1981 he has worked in the Department of Obstetrics and Gynecology at Vilnius State University as Assistant Professor. Since October 1987 he has been a guest at the Department of Obstetrics, University Hospital of Zurich, Switzerland, as a recipient of a Swiss National Research Grant. His main field of interest is obstetrical and Doppler ultrasound.

Twenty evaluations each were made of the a. carotis communis and of the a. femoralis in healthy non-pregnant persons as well as 20 evaluations of the a. umbilicalis in pregnant women with normal pregnancies at 32-40 weeks of gestation. For the a. carotis communis and a. femoralis, the angle of vessel insonation was determined. Analysis was performed on a Doptek Doppler spectrum analyser because Acuson 128 has no play-back analysis of Doppler frequency shifts.

The following evaluations were made for each of 10 cycles in every record:

- Intensity weighted mean frequencies (IW) given automatically from the Doptek - were converted into time average of space average velocities 
(TASAV) according to the Doppler shift equation: $\mathrm{f}_{\Delta}=2 \mathrm{f}_{0}(\mathrm{v} \cos \theta) / \mathrm{c}$ after insonation angle correction.

- Pulsatility index (PI), according to the formula [10]:

$P I=\frac{f_{\max }-f_{\min }}{f_{\text {mean }}}$

- Resistance index (RI), according to the formula [16]:

$R I=\frac{f_{\max }-f_{\min }}{f_{\max }:}$

For both formulas:

$f_{\max }-$ maximum of the maximal frequencies,

$f_{\min }-$ minimum of the maximal frequencies,

$f_{\text {mean }}-$ mean of maximal frequencies (envelope of the spectrum).

PI calculations were made using the following Doptek Doppler spectrum analyser programs:

$7 \mathrm{mx}-87 \%$ of the total sum of spectral amplitudes was taken as the criterion for maximum frequency envelope determination.

Table I. Number of cardiac cycles used by different authors to calculate blood flow velocity indices.

\begin{tabular}{lll}
\hline Author & Vessel & $\begin{array}{l}\text { Num- } \\
\text { ber } \\
\text { of } \\
\text { cycles }\end{array}$ \\
\hline Arduini D. et al. [1] & $\begin{array}{l}\text { fetal aorta } \\
\text { a. umbilicalis }\end{array}$ & $\begin{array}{l}10 \\
\text { a. carotis int. }\end{array}$ \\
& a. umbilicalis & 3 \\
Gerson A. G. et al. [6] & a. uterina & 5 \\
Giles W. B. et al. [7] & a. umbilicalis & 5 \\
Laurin J. et al. [13] & fetal aorta & 10 \\
McLennan F. M. et al. [14] & maternal aorta & $7-22$ \\
Mulders L. G. M. et al. [15] & a. umbilicalis & 2 \\
Rochelson B. L. et al. [17] & a. umbilicalis & 4 \\
Trudinger B. J. et al. [19] & a. umbilicalis & 5 \\
Wladimiroff J. W. et al. & a. uterina & 5 \\
[20] & a. carotis int. & 4 \\
Woo J. S. K. et al. [21] & a. umbilicalis & 4 \\
& middle cerebral & 3 \\
\hline
\end{tabular}

$15 \mathrm{mx}-95 \%$ of the total sum of spectral amplitudes was taken as the criterion for maximum frequency envelope determination.

Pen - manually tracing a maximum frequency curve envelope, using a light pen.

For RI calculations, a light pen was used and maximum systolic and diastolic frequencies were indicated manually.

Afterwards, the mean, standard deviation (SD) and coefficient of variation (CV) for 2, 3, 4 up to 10 averaged cycles were calculated for each of the indices. The coefficient of variation was calculated according to the formula:

$\operatorname{CV}(\mathrm{x})=\mathrm{s} / \mathrm{x} * 100 \%$,

were $\mathrm{s}=$ standard deviation, $\mathrm{x}=$ mean.

The coefficients of variation for PI, RI and TASAV from 10 averaged cycles were compared with the CVs of the respective indices from 2,3 , 4 up to 9 averaged cycles using the Wilcoxson signed rank test. The number of averaged cycles where the difference between the coefficients of variation became statistically insignificant was taken to be the point at which representative values of PI, RI or, respectively, TASAV are assured.

\section{3 'Results}

As is seen from figure 1, there may be great variation in the individual PI values from cycle to cycle in the a. umbilicalis. The number of cardiac cycles averaged had a strong influence on the resulting PI mean values. As figure 2 shows, averaging the individual PI values given in figure 1 over increasing numbers of cardiac cycles results in different PI mean values with each new cycle. However, a point is reached after which the mean values remain fairly stable. The point after which the mean values no longer vary to any significant degree was found to be different for the other blood flow velocity indices as well as for different vessels and for different calculation programs of the Doptek Doppler spectrum analyser.

For the a. carotis communis, the results for two sample analyses (Wilcoxon signed rank test) of the differences between the coefficients of variation of the mean values of PI, RI and TASAV from 10 averaged cycles and the coefficients of variation of, respectively, 2, 3, 4, 5, 6, 7, 8 and 9 averaged cycles are shown in figure 3 . The black marks 


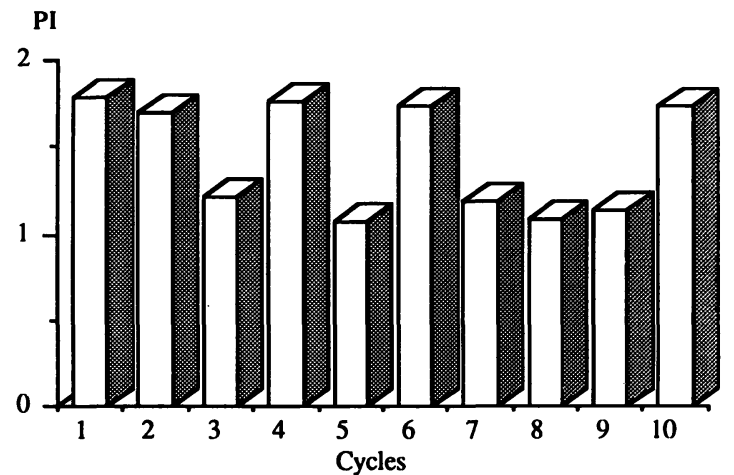

Figure 1. Values of PI in each of 10 separate consecutive cardiac cycles of the a. umbilicalis.

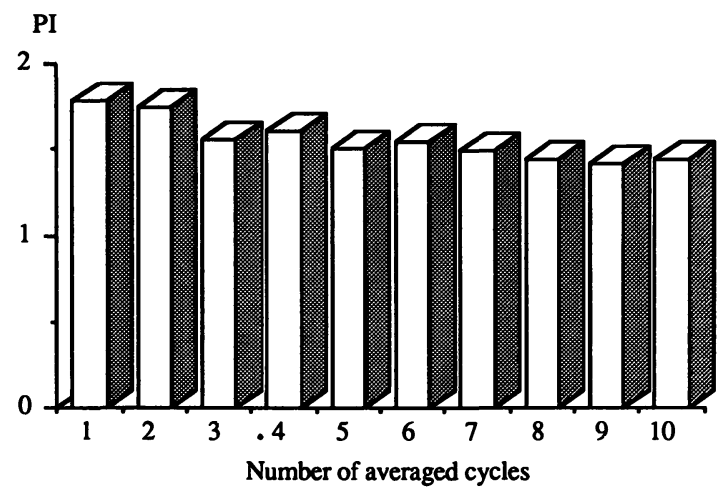

Figure 2. Mean values of PIs according to the number of cardiac cycles over which averaging took place. The same PI values per cycle are used as in Fig. 1, and the first value is the same as in Fig. 1 (the PI value for the first cycle). Thereafter, however, the mean values over, respectively, $2,3,4, \ldots 10$ cycles are given: $\left(\mathrm{PI}_{1}+\mathrm{PI}_{2}\right) /$ 2, $\left(\mathrm{PI}_{1}+\mathrm{PI}_{2}+\mathrm{PI}_{3}\right) / 3$ etc.

indicate the values at which differences between the coefficients of variation became statistically insignificant. PI evaluation with the $7 \mathrm{mx}$ and 15 $\mathrm{mx}$ calculation programs required averaging at least 7 cardiac cycles; evaluation with light pen, 5 cycles. RI evaluation with a light pen required 5 cycles. Three cycles were necessary for TASAV evaluation with the IW calculation program.

The results from the a. femoralis investigations are shown in figure 4. PI evaluation with the $7 \mathrm{mx}$ program required averaging 5 cycles; with light pen and the $15 \mathrm{mx}$ program, 6 cycles, and for the TASAV evaluation with the IW program, 7 cycles.

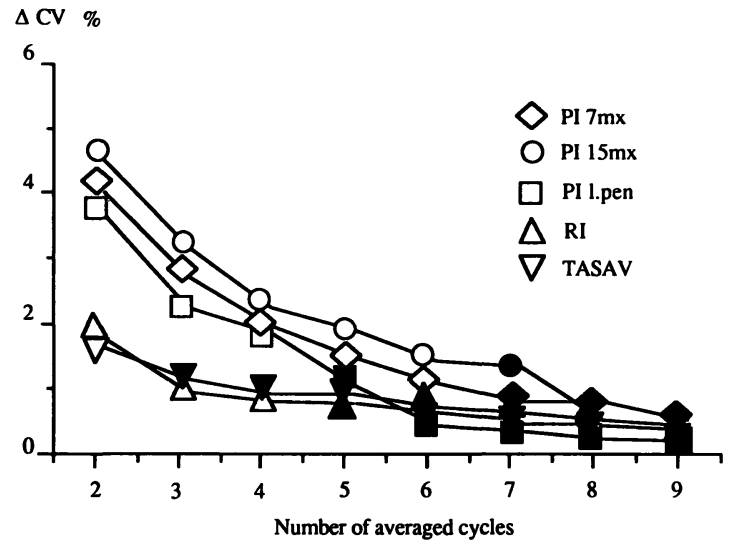

Figure 3. In the a. carotis communis, the differences between the coefficients of variation $(\Delta \mathrm{CV})$ from 10 averaged cycles and, respectively, $2,3,4,5,6,7,8$, and 9 averaged cycles of the mean values of PI calculated with $7 \mathrm{mx}, 15 \mathrm{mx}$ automatic and manual (light pen) maximum frequency envelope determination programs and RI and TASAV. The black marks indicate the values where differences were found to be statistically insignificant (Wilcoxon signed rank test).

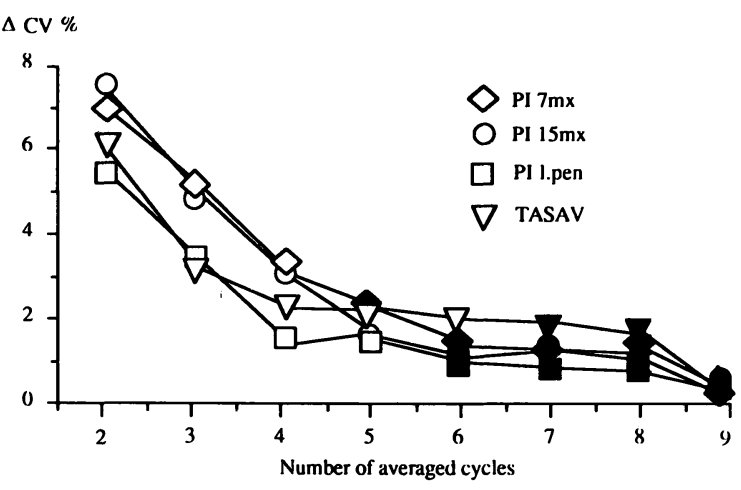

Figure 4. In the a. femoralis, the differences between the coefficients of variation $(\Delta \mathrm{CV})$ from 10 averaged cycles and, respectively, 2, 3, 4, 5, 6, 7, 8, and 9 averaged cycles of the mean values of PI calculated with $7 \mathrm{mx}, 15 \mathrm{mx}$ automatic and manual (light pen) maximum frequency envelope determination programs and TASAV. The black marks indicate the values where differences were found to be statistically insignificant (Wilcoxon signed rank test).

In figure 5 results are shown from the a. umbilicalis, where PI evaluation with the $7 \mathrm{mx}$ program required averaging 6 cycles, with the $15 \mathrm{mx}$ program, 8 cycles, and with light pen, 7 cycles. RI evaluation with light pen required averaging at least 5 cycles. 


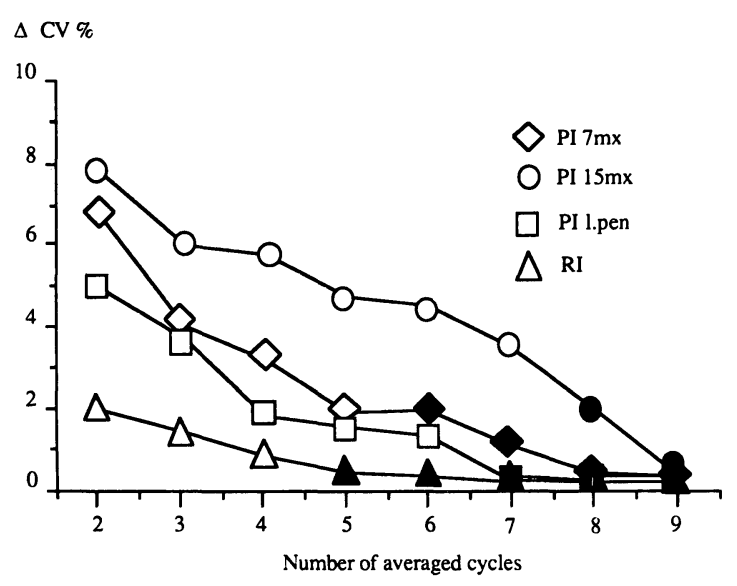

Figure 5. In the a. umbilicalis, the differences between the coefficients of variation $(\Delta \mathrm{CV})$ from 10 averaged cycles and, respectively, $2,3,4,5,6,7,8$, and 9 averaged cycles of the mean values of PI calculated with $7 \mathrm{mx}, 15$ $\mathrm{mx}$ automatic and manual (light pen) maximum frequency envelope determination programs and RI. The black marks indicate the values where differences were found to be statistically insignificant (Wilcoxon signed rank test).

\section{Discussion}

Doppler ultrasound is a widely used new technique for the assessment of blood flow velocity waveforms in fetal and adult medicine. Estimation of the Doppler signal spectrum is improved by using the traditional method of averaging several cardiac cycles. However, authors still use a wide variety of numbers of cardiac cycles for calculations of blood flow indices, from two [15] to ten $[1,13]$ or even more [14]. If only a small number of cardiac cycles is used for the mean value calculation, there can be differences in the interpretation of the normal values of the calculated indices due to the high individual variability. According to a report by Thompson [18], there is considerable variation in the spectrum for a single blood flow velocity waveform. This is slightly reduced after averaging over three cardiac cycles and substantially reduced after averaging over eleven. Erskine and Ritchie [4] analysed 100 consecutive waveforms from the umbilical artery of normal fetuses and determined that the standard error of the mean of PI was only
$2.7 \%$ when 10 cycles were sampled and did not greatly increase when only 5 cycles were examined. Kassam and coauthors [12] also agree with 5 averaged cardiac cycles for evaluation of blood flow velocity indices. On the other hand, using a large number of cardiac cycles (20 or more) for mean value calculation is time-consuming, and little is gained by averaging more than $15-20$ cycles [11].

It is seen from figure 2 that in the a. umbilicalis, PI mean values for 2,3 , or 4 cycles vary considerably; yet, if 5 or 6 cycles are averaged, the differences in the mean values level off, and the PI mean values remain fairly stable when $7,8,9$, or 10 cycles are averaged. Similar results were found for the a. carotis communis and a. femoralis. For this reason 10 averaged cardiac cycles were chosen as the point from which comparative analysis of the coefficient of variability of the mean was made.

Manual evaluation of the maximum frequency curve envelope for PI calculations produced different results than automatic PI evaluation did, although the differences were also dependent on the vessel from which measurements were made. The analysis of time average of space average velocities (TASAV) is most sensitive to "noise" interference. A single noise spike at the maximum or minimum limit of the spectrum analyser range will shift the mean dramatically [2]. This may be the reason that TASAV requires such a high number of cardiac cycles to be averaged in a. femoralis recordings.

The coefficient of variation is most useful as a descriptive tool in situations where a change in the conditions under which measurements are made alters the standard deviation in the same proportion as it alters the mean. The coefficient of variation then remains unchanged and is a useful single measure of variability.

We have thus found that the minimum number of cardiac cycles over which values should be averaged to ensure representative blood flow velocity measurements is dependent on the index being calculated, the vessel being studied and the evaluation program being used. An awareness of these facts should help prevent inaccurate conclusions when using Doppler ultrasound to measure blood flow velocity. 


\begin{abstract}
The aim of this study was to determine the minimum number of cardiac cycles necessary over which blood flow velocity representative of the situation (and not unduly influenced by sporadic irregularities). Blood flow was measured by Doppler ultrasound in the adult a. carotis communis, a. femoralis and fetal a. umbilicalis. The coefficients of variation (CV) for the Pulsatility Index (PI), Resistance Index (RI) and Time Average of Space Average Velocities (TASAV) from 10 averaged cycles were compared with the CVs of the respective indices from 2, 3, 4 up to 9 averaged cycles. The number of averaged cycles where the difference between the coefficients of variability became insignificant (Wilcoxon signed rank test) was taken to be the point at which representative values of PI, RI or, respectively, TASAV are assured. For PI evaluation for the a. carotis com-
\end{abstract}

munis with either the $7 \mathrm{mx}$ or $15 \mathrm{mx}$ calculation program one needs to average over 7 cardiac cycles. Manually determining the maximum frequency curve envelope, 5 cycles are sufficient. Using these same calculation programs for the a. femoralis, 5, 6 and, respectively, 6, cycles are sufficient for representative PI indices; for the umbilical artery, 6, 8 and, respectively, 7 cycles are necessary. For RI, 5 cycles are sufficient in both the a. carotis communis and a. umbilicalis by manual evaluation. For TASAV, a minimum of 3 cycles for the a. carotis communis and of 7 for the a. femoralis are necessary.

Thus the number of cardiac cycles which should be averaged is dependent on the vessel being examined, the index being calculated, and the program being used.

Keywords: Blood flow velocity, Doppler ultrasound, measurement technique, PI, RI.

\section{Zusammenfassung}

Bestimmung der minimalen Anzahl von Herzzyklen, die für eine repräsentative Flowmessung notwendig ist Ziel dieser Studie war die Bestimmung der Anzahl von Herzzyklen, die notwendig ist, um repräsentative Indizes zur Beschreibung des aktuellen Flows zu erhalten und eine fälschliche Beeinflussung durch sporadische Unregelmäßigkeiten auszuschließen. Mit einem gepulsten Doppler-Gerät (Acuson 128) wurden Flowmessungen in der A. carotis communis und A. femoralis beim Erwachsenen sowie in der fetalen A. umbilicalis vorgenommen und mit einem Doppler-Spectrum-Analyser (Doptek) ausgewertet. Die Variationskoeffizienten (CV) für den Pulsatilitätsindex (PI), den Widerstandsindex (RI) und die über Zeit und Intensität gemittelten Geschwindigkeiten (Time Average of Space Average Velocities, TASAV) von 10 gemittelten Zyklen wurden verglichen mit den Koeffizienten der genannten Indizes von 2, 3, 4 bis zu 9 Zyklen. Die Anzahl der gemittelten Zyklen, bei der die Unterschiede zwischen den Variationskoeffizienten nicht mehr signifikant waren (geprüft im WilcoxonTest), wurde als Diskriminante angesehen, die repräsentative Werte für PI, RI und TASAV lieferte. Zur Berech- nung des PI in der A. carotis communis unter Benutzung des $7 \mathrm{mx}$ - oder $15 \mathrm{mx}$-Programms muß man 7 Herzzyklen mitteln (dabei werden $87 \%$ bzw. 95\% der Summe der Spektren als Kriterium für die Berechnung der maximalen Frequenzen zugrunde gelegt). Benutzt man einen "Lichtschreiber" zur Berechnung der maximalen Frequenzkurven, sind 5 Zyklen ausreichend. Bei der A. femoralis sind mit den Programmen $7 \mathrm{mx}, 15 \mathrm{mx}$ und Lichtschreiber 5, bzw. 6 bzw. wiederum 6 Zyklen ausreichend, um repräsentative PI-Werte zu erhalten; in der A. umbilicalis sind es 6 bzw. 8 bzw. 7 Zyklen. Für den $\mathrm{RI}$ sind sowohl in der A. carotis communis wie auch in der a. umbilikalis bei manueller Berechnung 5 Zyklen ausreichend. Hinsichtlich TASAV sind in der A. carotis communis mindestens 3 , in der A. femoralis mindestens 7 Zyklen notwendig.

Das heißt, die Anzahl der zu mittelnden Herzzyklen ist abhängig von dem Gefäß, das untersucht wird, vom Index, der berechnet werden soll und vom angewendeten Programm. Im allgemeinen können 7 oder 8 Zyklen als ausreichend angesehen werden, um repräsentative Flowindizes $\mathrm{zu}$ erhalten.

Schlïsselwörter: Blutflußgeschwindigkeit, Dopplersonographie, Meßtechnik, PI, RI.

\section{Résumé}

Détermination du nombre minimum de cycles cardiaques nécessaire pour assurer des mesures représentatives de la vélocité sanguine

C'est l'objectif de cette étude de déterminer le nombre de cycles cardiaques nécessaires pour que les mesures de vélocité sanguine puissent être prises en compte en garantissant des indices représentatifs de la situation (et non influencés induement par des irrégularités sporadiques).
On a réalisé des mesures doppler de débits sanguins au niveau de la carotide primitive et de l'artère fémorale chez l'adulte et au niveau de l'artère ombilicale chez le fotus à l'aide d'un doppler pulsé ACUSON 128, et d'un analyseur de spectre Doppler DOPTEK. On a comparé les coefficients de variation (CV) de l'index de pulsatilité (PI), l'index de résistance (RI) et moyenne des vitessés moyennes durant un cycle cardiaque (TASAV) sur dix cycles moyennés avec les $\mathrm{CV}$ et les indices respectifs sur 
$2,3,4 \ldots$ jusqu'à 9 cycles moyennés. On a considéré comme étant le point pour lequel les valeurs de PI, RI ou respectivement TASAV étaient certaines le nombre de cycles moyennés où la différence entre les coefficients de variabilité devenait insignificante. Pour l'évaluation de PI au niveau de la carotide primitive, il est nécessaire de faire la moyenne sur plus de 7 cycles cardiaques que ce soit avec le programme de calcul $7 \mathrm{mx}$ ou $15 \mathrm{mx}$ (dans lesquels respectivement $87 \%$ et $95 \%$ de la somme totale des amplitudes de spectre sont pris comme critère de détermination de l'enveloppe de fréquence maximale). Si l'on se sert d'un crayon lumineux pour la détermination manuelle de l'enveloppe de la courbe de fréquence maximale, 5 cycles suffisent. En utilisant ces programmes de calcul ( $7 \mathrm{mx}, 17 \mathrm{mx}$, crayon) respectivement 5,6 et 6 cycles sont suffisants pour obtenir des indices PI représentatifs au niveau de l'artère fémorale; au niveau de l'artère ombilicale, 6,8 et 7 cycles sont nécessaires. Pour RI 5 cycles sont suffisants à la fois pour la carotide primitive et l'artère ombilicale en évaluation manuelle. Pour TASAV au moins 3 cycles sont nécessaires au niveau de la carotide primitive et 7 cycles au niveau de l'artère fémorale.

Ainsi, le nombre de cycles cardiaques qui doivent être moyennés dépend du vaisseau à étudier, de l'index à calculer et du programme utilisé. En règle générale, on peut accepter 7 ou 8 cycles cardiaques comme suffisants pour garantir des indices représentatifs de vélocité sanguine.

Mots-clés: Doppler, échographie, PI, RI, technique du mesure, vélocité sanguine.

\section{References}

[1] Arduini D, G Rizzo, C Romanini, S Mancuso: Fetal blood flow velocity waveforms as predictors of growth retardation. Obstet Gynecol 70 (1987) 7

[2] BEACH KW, DJ PHILlIPS: Doppler instrumentation for evaluation of arterial and venous disease. In: JAFFE CC (ed): Vascular and Doppler Ultrasound. Churchill Livingstone, New York 1984

[3] Eik-Nes SH, K Marsal, K Kristoffersen: Methodology and basic problems related to blood flow studies in the human fetus. Ultrasound Med Biol 10 (1984) 329

[4] ERSKINE RLA, JWK RITCHIE: Umbilical artery blood flow characteristics in normal and growth retarded fetuses. Br J Obstet Gynaecol 92 (1985) 605

[5] Gardin J, A Dabestani, K Matin, A Allfie, D Russel, WL HENRY: Reproducibility of Doppler aortic blood flow measurements: Studies on intraobserver, interobserver and day-to-day variability in normal subjects. Am J Cardiol 54 (1984) 1092

[6] Gerson AG, DM Wallace, RJ Stiller, D Paul, S WeINER, RJ BOLOGNESE: Doppler evaluation of umbilical venous and arterial blood flow in the second and third trimester of normal pregnancy. Obstet Gynecol 70 (1987) 622

[7] Giles WB, FX LaH, BJ Trudinger: The effect of epidural anaesthesia or caesarean section on maternal uterine and fetal umbilical artery blood flow velocity waveforms. Br J Obstet Gynaecol 94 (1987) 55

[8] GILL RW: Measurement of blood flow by ultrasound: accuracy and sources of error. Ultrasound Med Biol 11 (1985) 625

[9] GILL RW: Doppler Ultrasound - physical aspects. Seminars in Perinat 11 (1987) 292
[10] GosLing RG: Extraction of physiological information from spectrum analyzed Doppler shifted continuous wave ultrasound signals obtained noninvasively from the arterial system. In: HILL DM, BW WATSON (eds): IEE Medical Electronic Monographs 13-22. Peter Peregrinus, London 1976

[11] Greene FM, JK Beach, DE Strandness, JG Feu, DJ PHILLIPS: Computer based pattern recognition of carotid arterial disease using pulsed Doppler ultrasound. Ultrasound Med Biol 2 (1982) 161

[12] Kassam M, RSC Cobbold, P Zuech, KW JohNSTON: Quantification of carotid arterial disease by Doppler ultrasound. IEE Ultrasonics Symp Proc (1982) 675

[13] Laurin J, G Lingman, K Marsal, P-H Persson: Fetal blood flow in pregnancies complicated by intrauterine growth retardation. Obstet Gynecol 69 (1987) 895

[14] McLennan FM, NE Haites, JM Rawles: Stroke and minute distance in pregnancy: a longitudinal study using Doppler ultrasound. Br J Obstet Gynaecol 94 (1987) 499

[15] Mulders LGM, PFF Win, HW Jongsma, PR HeIN: A comparative study of three indices of umbilical blood flow in relation to prediction of growth retardation. J Perinat Med 15 (1987) 1

[16] Pourcelot L: Applications cliniques de l'examen Doppler transcutane. In: Peroneu P (ed): Velocimetric ultrasonor Doppler. Inserm 34 (1974) 213

[17] Rochelson BL, H Shulman, A Fleischer, G FarMAKIDES, L BRACERo, J DUCEY, D WinTer, B PENNY: The clinical significance of Doppler umbilical artery velocimetry in the small for gestational age fetus. Am J Obstet Gynecol 156 (1987) 1223 
[18] ThомpSON RS: Blood flow velocity waveforms. Seminars Perinat 11 (1987) 300

[19] Trudinger BJ, WB GILES, CM COOK: Flow velocity waveforms in the maternal uteroplacental and fetal umbilical circulations. Am J Obstet Gynecol 152 (1987) 155

[20] WladimirofF JW, JAGW vD WijngaARD, S DEGANI, MJ NOORDAM, JV EYCK, HM, TONGE: Cerebral and umbilical arterial blood flow velocity waveforms in normal and growth-retarded pregnancies. Obstet Gynecol 69 (1987) 705
[21] Woo JK: Middle cerebral artery Doppler flow velocity waveforms. Obstet Gynecol 70 (1987) 613

Received August 24, 1988. Revised November 14, 1988. Accepted December 1, 1988.

Juozas Kurmanavichius

Guest Assistant Professor

Department of Obstetrics

University Hospital of Zurich

Frauenklinikstr. 10

CH-8091 Zürich

Switzerland 